\title{
Modelling Marten (Martes americana) Movement Costs in a Boreal Forest: Effects of Grain Size and Thematic Resolution
}

\author{
Ophélie Planckaert and André Desrochers \\ Centre d'étude de la forêt, Université Laval, Pavillon Abitibi-Price, 2405 rue de la Terrasse, Université Laval, QC, Canada G1V $0 A 6$ \\ Correspondence should be addressed to André Desrochers, andre.desrochers@sbf.ulaval.ca
}

Received 24 October 2011; Revised 30 March 2012; Accepted 17 April 2012

Academic Editor: Daniel Rubenstein

Copyright () 2012 O. Planckaert and A. Desrochers. This is an open access article distributed under the Creative Commons Attribution License, which permits unrestricted use, distribution, and reproduction in any medium, provided the original work is properly cited.

\begin{abstract}
We investigated landscape resistance to movements of American marten (Martes americana) based on snow-tracking data. We generated movement cost maps of the study area with different grain size, thematic resolution, and habitat-specific resistance to movements. We compared simulated tracks obtained from resistance maps to real tracks plotted along transects that we surveyed in winters 2004 to 2008 at the Montmorency Forest, Quebec, Canada. Simulated tracks were located at the intersection between least-cost paths simulated across the study area and transects. We used nearest-neighbour distances between simulated and real tracks to assess the performance of resistance maps and estimate landscape resistance parameters. Simulations with specified costs to movement for open areas, young forest, and mature forest performed better than simpler resistance scenarios, suggesting that resistance to marten movements differed among those landscape attributes that were considered. Simulations with a map grain size of $100 \mathrm{~m}$ performed significantly better than 5, 25, and $300 \mathrm{~m}$, possibly because of gap crossing avoidance. Model performance (compared to null model) was maximal when resistance to movement in open habitat was set to 20 times higher than in mature forest, but uncertainty around this estimate was large. This research demonstrates that presence-only (point) data can be used to parameterize movements using spatially explicit modelling.
\end{abstract}

\section{Introduction}

Habitat selection studies have long assumed that access to habitats is a negligible constraint for animal movements within landscapes [1], but access limitations that are attributable to roadways and forest fragmentation are increasingly recognized [2]. Movement constraints are governed by spatial patterns of resource used to maximize fitness (e.g., access to critical resources and avoidance of predation). They reduce connectivity [3] within the established home range of animals and limit accessibility of habitat patches to dispersing organisms [4], thereby affecting population dynamics. Thus, the occurrence of an animal in a habitat may depend on the surrounding matrix, and the consideration of movement constraints appears to be crucial in the development of habitat selection models $[1,5,6]$. Spatially explicit simulations including least-cost paths $[7,8]$ have become increasingly popular for modelling optimum movement routes of animals. Least-cost models can simulate animal movements based on the configuration of different spatial features within a heterogeneous landscape, and the hypothetical resistance to movement associated with them. In testing various hypothetical management scenarios, Sutcliffe et al. [9] concluded that least-cost path simulation is a powerful tool in landscape management planning. Results of Broquet et al. [10] showed that inclusion of the resistance of landscape features in models better explained marten (Martes americana) genetic patterns than did Euclidean distances. Desrochers et al. [11] also better evaluated ovenbird (Seiurus aurocapilla) movement resistance in open areas at small and large scales with least-cost paths simulations than with Euclidean distances. These studies show that resistance to movement across the landscape contributes to shaping movement and gene flow in heterogeneous landscapes.

Predicting costs to movement is essential for identifying and preserving habitat configurations that promote gene flow and, thus, species persistence [9]. When Hargis et al. [12] found lower capture rates of American martens in small 
forest patches, they suggested four factors that contributed to decreased occupancy, roughly corresponding to (1) lack of adequate shelter; (2) absence of prey; (3) exposure to harsh weather; (4) interspersion with low-quality habitats. The combination of these four factors could translate into a global "perceived" movement resistance by martens [13]. However, such an aggregate, "perceived" movement resistance has rarely been quantified, leading many wildlife scientists to estimate input parameters in least-cost path models purely as expressions of expert opinion [14]. Some authors have criticized this practice of using habitat suitability models to build cost surfaces [15], arguing that it may induce errors in predictions if models are not validated [16]. To circumvent this problem, methods are needed to provide truly empirical movement resistance estimates. Recent studies have attempted to estimate resistance by comparing model fit to real data [17-19]. Recently, Driezen et al. [20] presented a method of validating the best least-cost path tested model with real dispersal paths, and reiterated the necessity to work with habitat specialist species to estimate cost values throughout the landscape. Cushman and Lewis [21] predicted landscape resistance from movement data and expressed the need for applying correct landscape variables and thematic resolution values to resistance models. Cushman et al. $[22,23]$ used a path randomization approach in which the reference path's topology is preserved by randomly shifting and rotating it to produce a group of available paths to which it can be compared.

The first objective of this study was to evaluate the performance of various landscape resistance maps, based on an approach that can be easily applied to other study areas without perturbing animals during a critical period. In spatially explicit models, the application of movement resistance values to different land cover types involves creating grid maps and choosing their parameterization values. The second objective of this study was to optimize marten movement resistance, map grain size, and thematic resolution to estimate parameterization values and help in building future models of landscape-level genetics related to this species. Map resolution of resistance surfaces should be based on structural and functional connectivity rather than being determined solely from landscape or environmental features [14]. Previous studies have shown that movements of dispersing juveniles or adults foraging within their home-ranges depend on the fragmentation level of the landscape [22]. In resistance surfaces, map resolution cannot include connectivity of habitats across the landscape, hence the interest in simulating least-cost paths that progress through landscapes according to the configuration of different spatial features.

To meet the objectives of this study, we compared the resistance of open, young, and closed forest stands to movements of American marten during winter at four map grain sizes. We estimated relative movement resistance inside versus outside of forest cover by comparing the spatial proximity of least-cost path simulations to occurrence data, with different resistance parameters assigned to forests, roads, and clear cuts. We assumed that the marten tracks that we observed were a result of martens following least-cost-paths

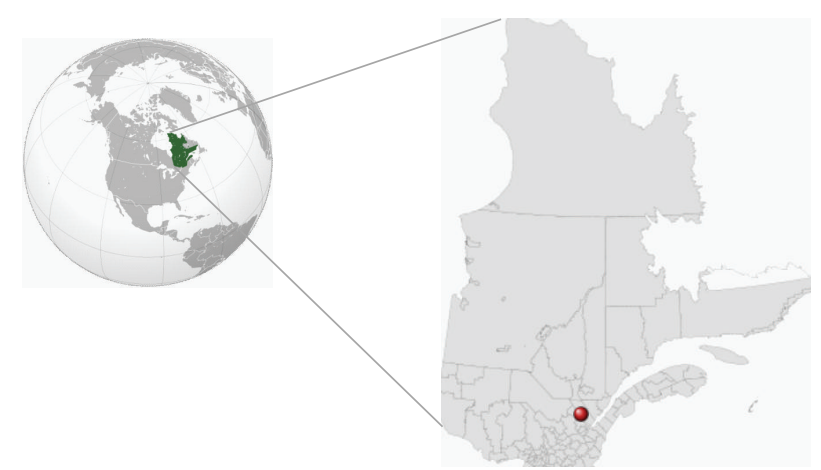

FIGURE 1: Location of the Montmorency Forest within the province of Quebec (Canada).

across the study area. Thus, we simulated least-cost-paths (LCPs) across the landscape, simulated tracks where those LCPs intersected transects sampled for real tracks, and compared simulated tracks with the observed marten tracks. Our approach illustrates the relevance of presence-only data for the comparison of mechanistic hypotheses pertaining to animal movement.

\section{Materials and Methods}

2.1. Study Area. We carried out field work in Montmorency Forest, Quebec, Canada $\left(47^{\circ} 19^{\prime} \mathrm{N}, 71^{\circ} 9^{\prime} \mathrm{W}\right.$; Figure 1). This $66 \mathrm{~km}^{2}$ boreal forest is managed for timber and recreation, but it has a long history of use for teaching and research by Laval University. Balsam fir (Abies balsamea) and black spruce (Picea mariana) were the dominant tree-species, followed by white birch (Betula papyrifera), white spruce (Picea glauca), and trembling aspen (Populus tremuloides). From January to March (1971-2000), daily mean temperatures were $-15.8^{\circ} \mathrm{C} \pm 2.5^{\circ} \mathrm{C},-14.1^{\circ} \mathrm{C} \pm 2.9^{\circ} \mathrm{C}$, and $-7.9^{\circ} \mathrm{C} \pm$ $2.5^{\circ} \mathrm{C}$, respectively [24]. Annual precipitation as snow (November to April) generally exceeded $6 \mathrm{~m}$ [24]. Peak snow accumulation varied from 1 to $2 \mathrm{~m}$ approximately, depending on years, forest cover, and topography (unpubl. data from snow depth surveys and automated weather station). The topography is hilly, with elevations ranging from 750$1000 \mathrm{~m}$. One of the management objectives of Montmorency Forest is to recreate a forest stand mosaic that reflects natural disturbances [25]. To reach this goal, harvest patches are separated into three size groups ( $<10$ ha, 10-30 ha, and 30$100 \mathrm{ha}$ ) and each size group has the same total area, which results in the creation of many small patches and few large patches. Moreover, the managers of Montmorency Forest have staggered harvests through time to obtain four main groups of stand ages (based on sylvicultural practice): (1) regenerating: 0-20y, (2) young: $21-40 \mathrm{y}$, (3) mature: 41$60 \mathrm{y}$, and (4) old-growth: $>60 \mathrm{y}$. Fine-grained sylvicultural practices have resulted in a very dense road network $\left(2.91 \mathrm{~km} / \mathrm{km}^{2}\right)$ across the area. Trapping and hunting have not been allowed, but recreational activities such as crosscountry skiing and walking are permitted. 
2.2. Forest Data. All of the forest inventory data (stand age, cover type, stand limits, road networks) were provided by the managers of the Montmorency Forest who have compiled datasets from aerial photographs (scale $1: 10000$ ) and GPS. Every year, stand characteristics (age, height, density, etc.) are ground-truthed at control points.

2.3. Snow-Tracking. We documented the spatial distribution of marten tracks by snow-tracking each winter (1 January-31 March) from 2004 to 2008. Snow-tracking consisted of locating marten tracks along transects traversing all habitat types in the Montmorency Forest. Transects were conducted on all unplowed forestry roads and trails (length $200 \mathrm{~m}$ to $5 \mathrm{~km}$ ) and along a random sample of straight N-S or E-W lines (length $500 \mathrm{~m}$ to $2 \mathrm{~km}$ ) taken from 67 lines placed along a grid (500 $\mathrm{m}$ spacing) superimposed upon the study area. Each transect was inventoried only once per winter, on snowshoes or on a snow-mobile operating at very low speed. Snow-tracking occurred only when neither snow falls $>3 \mathrm{~cm}$ nor wind speeds $>30 \mathrm{~km} / \mathrm{h}$ were forecast, because in these cases, snow tracks are covered or swept away [26]. Track quality was described as low (single feet not distinguished), good (feet distinguished), or high (toes distinguished), with only good- and high-quality tracks being included in analyses. We did not follow marten tracks, but we recorded each marten path that crossed a transect as a point feature with a GPS receiver (Trimble GeoExplorer; Figure 2). Paths that crossed the transect several times over short distances $(<100 \mathrm{~m})$ were likely to be from the same individual but we did not consider this to be a statistical issue because we used mean nearest-neighbour distances from several tracks as statistical units (see Section 2.10). All tracks showing the mustelid two-print track pattern, with two-print widths ranging from $8-13 \mathrm{~cm}$, were assumed to be marten [27]. The presence of fisher (Martes pennanti) is unusual in the area, so we assumed that all tracks with this pattern were marten.

2.4. Resistance in Open Areas. We arbitrarily ascribed the highest resistance to movement in open areas, with ten values ranging from 4 to 1000 (constant set of values in mature forest, see [28]). Minimal resistance to open areas was set to 4 in order to vary young forest resistance value relative to the resistance in open habitat with ratios of 14,12 and 34 . Resistances $>1000$ often generated simulated movements along the border of the study area and were assumed to be out of a biologically realistic range for marten. Due to habitat selection by American marten [29], we assumed that mature forest stands offered the lowest resistance to marten movements, and set its value to 1 in all resistance maps [28].

2.5. Thematic Map Resolution. We created three scenarios of movement resistance for marten that varied in the cost values that we assigned to different habitat types (Figure 3 ). Each scenario was described with either two or three habitat categories. American marten in Quebec are known to be a specialist of dense and mature forest cover because they select habitat types according to vertical structure and

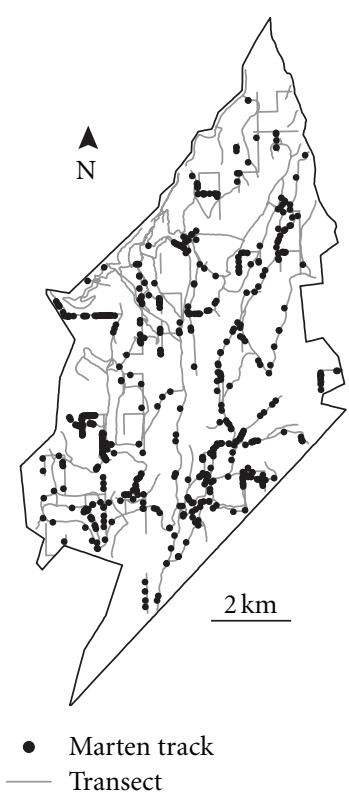

FIGURE 2: Transects sampled (lines) and marten tracks recorded (dots) in January-March 2008, at Montmorency Forest, Quebec, Canada (Projected Coordinate System: NAD83 NTM Zone 7).

structural features like snags and stumps [29]. Thematic map resolution was based on known marten habitat requirements in winter at the Montmorency Forest, that is, avoidance of $0-10 \mathrm{y}$-old stands, significant preference for $>30 \mathrm{y}$-old stands, and weak avoidance of 11-30 y-old stands [30]. A first scenario partitioned the landscape into "Open" areas (0 to $10 \mathrm{y}$-old stands, roads, rivers, lakes, peat bogs, gravel-pits, and islands) and "Forest" (>10 y-old forests). A second scenario partitioned the landscape into "Open" areas ( $>25 \mathrm{~m}$ from forest), "Edge" (Open areas $<25 \mathrm{~m}$ from forest), and "Forest" (>10 y-old). Resistance values for forest edges were set as half the resistance of open areas. This second scenario was aimed to evaluate forest border effect on marten movements, based on field observations that marten tracks were more often recorded on narrow roads and in the first few meters of open areas than in "core" open habitats. A third scenario partitioned the landscape into: "Open habitat," "Young forest" (11 to $30 \mathrm{y}$-old), and "Mature" (>30 y-old), with no edge effect. The latter scenario was subdivided in three subgroups, according to the resistance of young stands relative to that of open areas (ratio $=1 / 4,1 / 2$, or $3 / 4$; Table 1 ; relative cost weights [28]). Each scenario was represented by its own series of 10 maps differing by resistance in open areas (see above).

2.6. Map Grain Size. Map grain can be an important issue in least-cost path modelling [31]. Thus, we ran all analyses with four map grain sizes. We converted each map layer from vector to raster form, with map grain sizes of 5, 25, 100, and $300 \mathrm{~m}$. Small map grains led to uninterrupted forest roads and rivers, while coarser map grains created bridges across those linear features (Figure 4). 

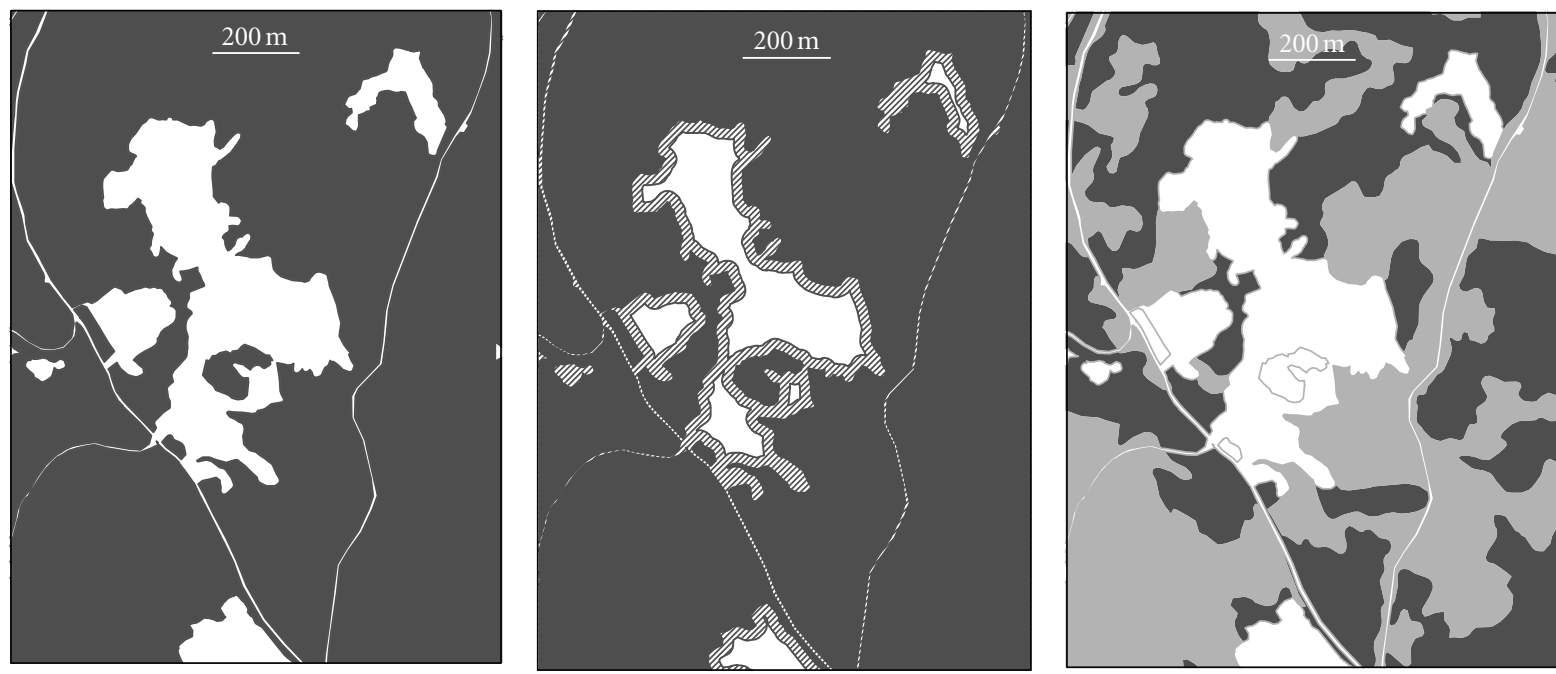

Forest
Open

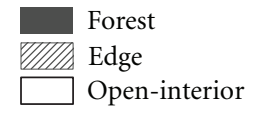

(a)

(b)

(c)

FIgURE 3: Three habitat resistance scenarios, applied to a selected part of the Montmorency Forest, Quebec, Canada.

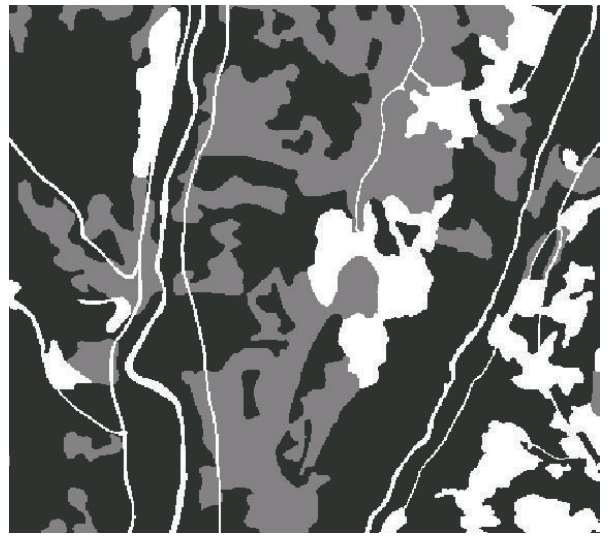

(a)

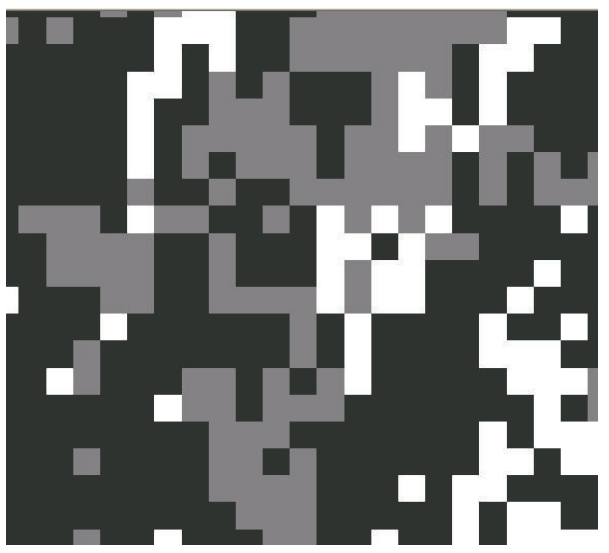

(c)

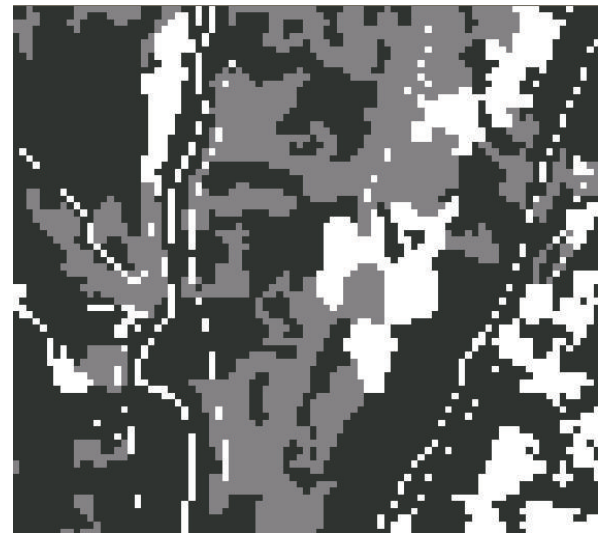

(b)

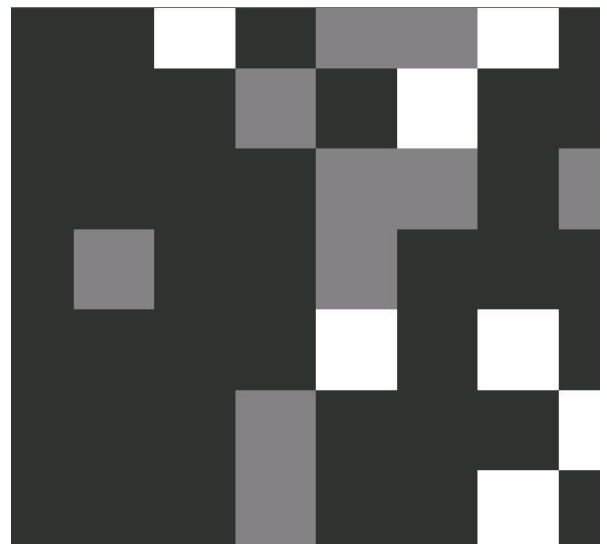

(d)

FIGURE 4: Landscape matrix-grid in a portion of the Montmorency Forest, with varied grain. Map grain $=5 \mathrm{~m}(\mathrm{a})$, $\mathrm{map}$ grain $=25 \mathrm{~m}(\mathrm{~b})$,

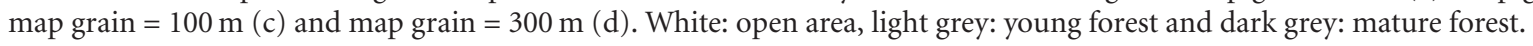


TABLE 1: Example of resistance values in young forest when the landscape layer is open/young/mature and the resistance value in the open is set to 12 .

\begin{tabular}{|c|c|c|c|}
\hline \multirow{2}{*}{$\begin{array}{l}\text { Resistance ratio (Young } \\
\text { forest: Open areas) }\end{array}$} & \multicolumn{3}{|c|}{ Resistance } \\
\hline & Mature forest & Young forest & Open areas \\
\hline $1: 4$ & 1 & 3 & 12 \\
\hline $1: 2$ & 1 & 6 & 12 \\
\hline $3: 4$ & 1 & 9 & 12 \\
\hline
\end{tabular}

Table 2: Model composition. Each line in the Table led to 10 cost surfaces, since 10 values were assigned to resistance in open areas for each of these combinations. Without null models, 200 cost surfaces were thus created.

\begin{tabular}{llc}
\hline Map grain & Thematic resolution & $\begin{array}{c}\text { Ratio of the resistance in young } \\
\text { forest compared to open areas }\end{array}$ \\
\hline \multirow{4}{*}{$5 \mathrm{~m}$} & Open-forest & - \\
& Open-edge-forest & - \\
& Open-young-mature & $1 / 4$ \\
& Open-young-mature & $1 / 2$ \\
& Open-young-mature & $3 / 4$ \\
\hline \multirow{4}{*}{$25 \mathrm{~m}$} & Open-forest & - \\
& Open-edge-forest & - \\
& Open-young-mature & $1 / 4$ \\
& Open-young-mature & $1 / 2$ \\
& Open-young-mature & $3 / 4$ \\
\hline \multirow{3}{*}{$100 \mathrm{~m}$} & Open-forest & - \\
& Open-edge-forest & - \\
& Open-young-mature & $1 / 4$ \\
& Open-young-mature & $1 / 2$ \\
& Open-young-mature & $3 / 4$ \\
\hline \multirow{3}{*}{$300 \mathrm{~m}$} & Open-forest & - \\
& Open-edge-forest & $1 / 4$ \\
& Open-young-mature &
\end{tabular}

2.7. Null Model. A null model was also generated, for which resistance values were set to one in all habitat types [32]. To summarize, we generated 201 resistance maps for each year, composed of 10 resistance levels in the open $\times 5$ scenarios $\times 4$ map grains, plus a null model (constant resistance) (Table 2).

2.8. Least-Cost Path Analysis. We used the least-cost path method [7] to simulate movements of American marten across cost surfaces, where grid cells are parameterized according to predicted costs of marten movement. ArcGIS 9.3 COSTDISTANCE and COSTPATH tools [33] were used to calculate the cumulative cost of each cell in the landscape and to link source and destination cells with the minimal cumulative cost. The aerial photos of the Montmorency forest are updated each year, which enables us to have yearspecific maps. Every year and for each of the 201 resistance
TABLE 3: Sampling effort of snow-tracking from 2004 to 2008.

\begin{tabular}{|c|c|c|c|}
\hline \multirow{2}{*}{ Year } & \multicolumn{2}{|c|}{ Total transect length $(\mathrm{km})$} & \multirow[t]{2}{*}{ Number of marten tracks } \\
\hline & $\begin{array}{c}\text { On forestry } \\
\text { roads and trails }\end{array}$ & $\begin{array}{l}\text { Outside of } \\
\text { roads and trails }\end{array}$ & \\
\hline 2004 & 89 & 39 & 259 \\
\hline 2005 & 86 & 19 & 260 \\
\hline 2006 & 138 & 46 & 291 \\
\hline 2007 & 116 & 28 & 247 \\
\hline 2008 & 145 & 43 & 610 \\
\hline Total & 574 & 175 & 1667 \\
\hline
\end{tabular}

maps (varying thematic resolution, map grains, and cost assignments), we simulated marten movement paths connecting 100 random points along the western edge of the study area to 100 random points on the eastern edge of the study area. Simulated paths may represent the paths of several real martens, because some marten home-ranges (1$96.6 \mathrm{~km}^{2}$, depending on conditions $\left.[34,35]\right)$ cannot cover the width of the forest $(3-16.5 \mathrm{~km})$. Therefore, the method did not assume that the animal had perfect knowledge of the whole landscape.

2.9. Simulated versus Observed Track Locations. Once leastcost paths were obtained, we generated "simulated tracks" at each point where least-cost paths intersected a transect sampled in the field. Each cost surface was then tested by comparing location of its simulated tracks with location of our observed tracks. For each of these simulated tracks, we first calculated the distance to the nearest observed track (minimum distance). Second, we weighted each distance by the inverse of the number of hours passed between the last climatic disturbance in the forest (wind speed $>20 \mathrm{~km} / \mathrm{h}$ or snow fall $>3 \mathrm{~cm}$ ) and the time when the marten track was observed. Climatic data were recorded hourly by an automated weather station [24] and were consulted every day prior to working in the field. Had we not weighted distances between observed and simulated tracks, a long time between tracking and climatic disturbance would have artificially brought real tracks close to simulated tracks, because the number of tracks increases as the snowless days accumulate, thereby decreasing the mean distance between simulated and observed tracks.

2.10. Comparing Resistance Scenarios. The performance of each cost surface was evaluated from the 100 weightedmean distances between real and simulated tracks that had been acquired with the 100 least-cost paths. Total length of covered transects varied between years, which led to a difference in the number of marten tracks recorded every year (Table 3). The years with a larger number of observed tracks resulted in smaller distances between simulated and observed tracks. To eliminate the year effect due to marten track density, performance of each model was compared with performance of the null model of the corresponding year. The performance of null model was measured as the median of the 100 weighted-mean distances between observed and 
TABle 4: Percentage of the 500 simulation for which mean distance is smaller than the median of mean distances for null model of the corresponding year. Fractions in parentheses represent resistance in young forest relative to resistance in open areas. Percentages significantly greater than 50 (better than null model) are shown in bold typeface. Results with $100 \mathrm{~m}$ grain are shown.

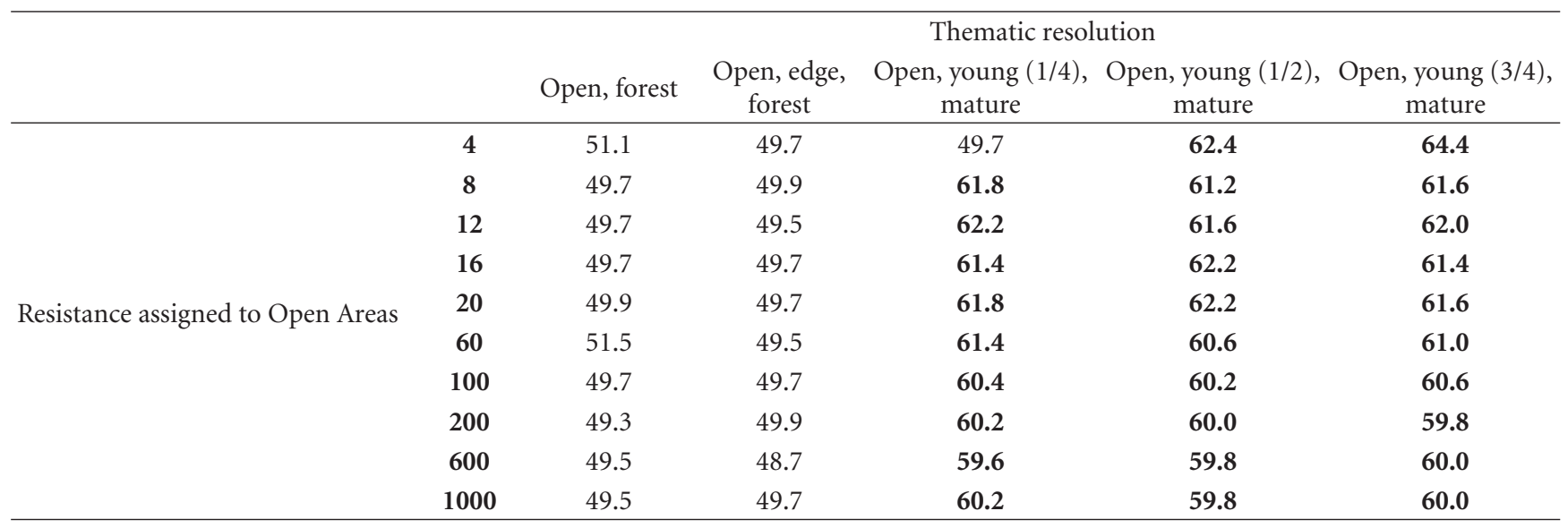

simulated tracks. We used medians instead of means because the overall distribution of weighted-mean distances was skewed to the right ( kkew $=1.71$, Agostino test: $z=22.8, P<$ 0.001 ). The performance of each of the 201 cost surfaces was expressed as the proportion of 500 least-cost paths (5 years, 100 paths in each year) that showed a mean distance that was smaller than the performance for the null model of the corresponding year. The performance of each simulated path (better than null model or not) was considered as an independent Bernouilli trial. Thus, we analyzed model performance as a proportion of models that were better than the null model with generalized linear models using a binomial error structure and logit link function (PROC GENMOD, SAS v. 9.1, Cary, NC, USA).

\section{Results}

Open areas, young and mature stands, respectively, covered $19 \%, 25 \%$, and $56 \%$ in 2004 (variation of $1.6 \% \max$ for each habitat type between 2004 and 2008). Each year we recorded locations of $>247$ marten tracks on over $100 \mathrm{~km}$ of transects (Table 3). Mean time without snow or strong winds before sampling was $95.7 \mathrm{~h} \pm 29.8 \mathrm{~h}$ ( $N=749$ transects $)$. Because transect length varied from year to year, the number of tracks that were simulated each year ranged from 131791 to 240643 . Some simulated paths did not cross transects and, therefore, did not generate the creation of simulated tracks. For these models, the numbers of simulated paths that were used to estimate performance were less than 500 .

3.1. Thematic Map Resolution. Varying thematic resolution affected the performance of least-cost path models. Of the 200 cost surfaces, 127 (63.5\%) performed better than the corresponding null model, and 53 of these performed significantly better $(P<0.05)$. Cost surfaces with open and forest areas $(\mathrm{OF})$, and simulations with forest, edge, and open areas (OEF) did not perform significantly better than null models. After accounting for map grain and movement resistance in open areas (Type 3 tests, SAS PROC GENMOD), models considering edges as less resistant to movements than "core" open areas did not perform better than models with edges as resistant as "core" open areas (linear contrast OF versus OEF, $\chi^{2}<0.01$, df $=1, P>0.9$ ). After accounting for map grain and resistance in the open, adding movement resistance estimates that were specific to young stands significantly improved the performance of models (linear contrast, OF/ OEF versus OYM simulations, $\chi^{2}=318.52$, $\mathrm{df}=1$, $P<0.0001$; see Table 4 for results with $100 \mathrm{~m}$ grain). After accounting for grain size and resistance in open areas, models with movement resistance in young stands set at $75 \%$ of that in open habitat performed significantly better than when the ratio was set at $25 \%$ (linear contrast, $\chi^{2}=4.73$, df $=1, P=$ $0.03)$. Changes in relative movement cost in young stands had a very small impact on model performance compared to grain size (Figure 5). Simulations with resistance in young stands set at $50 \%$ of that in open areas yielded intermediate results (linear contrasts with $25 \%$ and 75\% resistances: $\chi^{2}<$ $1.5, \mathrm{df}=1, P>0.22)$.

3.2. Map Grain Size. Map grain size had a substantial effect on movement path selection after accounting for edge, thematic resolution, and movement resistance in open canopy locations (Figure 5). Map grain size of $100 \mathrm{~m}$ performed better than those of 5, 25, or $300 \mathrm{~m}$ (linear contrasts: $\chi^{2}>80.0$, $\mathrm{df}=1, P<0.0001)$. Simulations with grains of $25 \mathrm{~m}$ also performed better than those with grains of $5 \mathrm{~m}\left(\chi^{2}=5.1\right.$, $\mathrm{df}=1, P=0.02)$, but the difference between $25 \mathrm{~m}$ and $5 \mathrm{~m}$ simulations was trivial (Figure 5). Grain size of $300 \mathrm{~m}$ did not perform better than any other grain size (linear contrasts with grains of 5 and $25 \mathrm{~m}: \chi^{2}<1.50, \mathrm{df}=1, P>0.2$ ).

3.3. Movement Resistance in Open Areas. After accounting for forest edge, thematic map resolution, and map grain, model performance was the highest when hypothetical resistance to movement in open areas was 20 times higher than in mature forest (Figure 6). The latter resistance of $20 \times$ did 


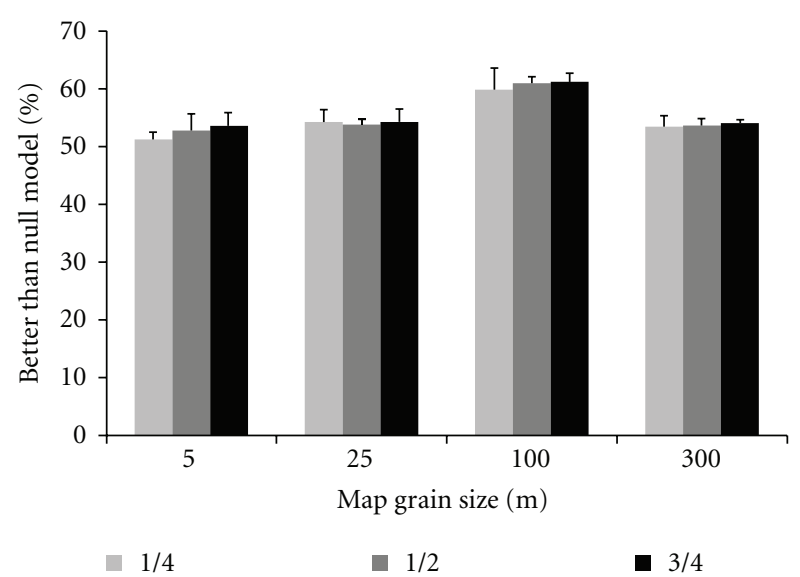

Figure 5: Mean (SE) performance of simulations with 10 movement resistances associated with open habitats relative to resistance assigned to young forests $(1 / 4,1 / 2$, and $3 / 4)$, and across varying grain size. Performance was defined as the percentage of the 500 simulation for which mean distance was smaller than median of mean distances for the null model of the corresponding year.

not perform significantly better than the other resistances (linear contrasts, $P>0.05$ ), but the lowest five resistances to movement, as a group, performed better than the highest five resistances (linear contrast, $\chi^{2}=4.5$, $\mathrm{df}=1, P<0.03$ ). Using all models weighted by their performance, the mean estimate of movement resistance in open habitats was 45.5, but $95 \%$ confidence limits covered the entire range of hypothetical resistances, making this estimate unreliable.

\section{Discussion}

We showed that simple assumptions about marten movement can explain a nonnegligible part of the distribution of marten activity in a managed forest, particularly at coarse levels of map grain. Performance of thematic map resolutions varied significantly depending on assumptions about resistance to movement in open areas and regenerating forest stands. Robinson [36] suggested that American martens avoided venturing far into open areas in winter. He found that they never went more than 25 yards $(\approx 23 \mathrm{~m})$ into open habitats despite the presence of bait. Yet, we found that considering forest edges as less resistant to movement than areas far into open habitat did not improve simulation performance. The absence of a difference in resistance between open areas and edges may have arisen from a difference between movement resistance of roads and clear-cut edges, both of which were subsumed in the "edge group" in our study. In support of this idea, marten tracks were seldom observed in the first $25 \mathrm{~m}$ of open stands near forest, but they were often recorded on narrow roadways (O. Planckaert, pers. obs.). However, these field impressions might have arisen from the high sampling effort on paths compared to that in open areas. A concurrent study in the Montmorency Forest found that American martens approached forest road and clear-cut edges similarly [37].

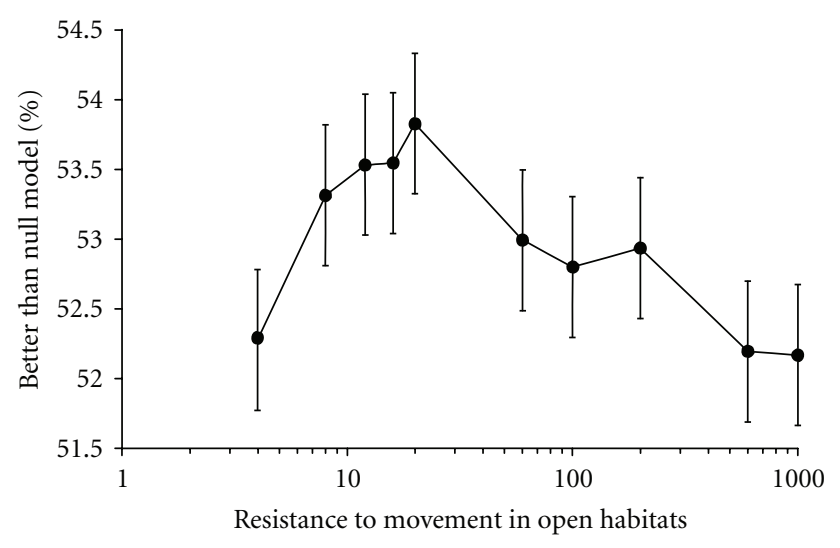

Figure 6: Mean (SE) performance of simulations with 10 movement resistances associated with open habitats. Performance was defined as the percentage of the 500 simulation for which mean distance was smaller than median of mean distances for the null model of the corresponding year. Performance estimates were obtained after accounting for forest edge, thematic map resolution and map grain size.

The allocation of an intermediate resistance to young forest ( 11 to $30 \mathrm{y}$-old stands) at a $100 \mathrm{~m}$ grain size approximated best the observed track locations. This result suggests that stands of young forest are not as permeable to marten movement as mature stands are. Alternatively, by including both young and mature forests in our model, we may have incorporated factors that were indirectly related to movement cost, such as prey densities specific to stand ages. In winter, martens hunt mostly large prey such as Northern flying squirrels (Glaucomys sabrinus), American red squirrels (Tamiasciurus hudsonicus), and snowshoe hares (Lepus americanus) [38] and feed on microtine rodents only incidentally [39]. In our study area, squirrels and hares occurred in similar densities in young, regenerating, and old forest stands [40] and thus prey density in forest is unlikely to have affected our results. However, the lack of foraging opportunities in open areas may have increased movement cost in these habitats.

Thematic maps with $100 \mathrm{~m}$ grain size better described landscape structure that is perceived by marten than did maps with finer or coarser grains. Broquet et al. [10] estimated least-cost paths with six grain sizes $(10,25,50,75,100$, and $500 \mathrm{~m}$ ) to evaluate the effect of landscape structure on dispersal of American martens, and did not find significantly different results between them, except at $500 \mathrm{~m}$ for which performance was lower. In our study, maps with $100 \mathrm{~m}$ grain size led to discontinuous roads and simulated more realistic marten track locations than did finer and coarser map grains, probably because of the creation of "cracks" (or bridges) in the maps. Rothley [41] defined "cracks" as the shortcuts across costly linear barriers that were represented in a raster form. This suggests that forestry roads are highly permeable to marten movements. In a forest where road network density is particularly high, such as was the case here, these "cracks" may represent locations on narrow roads that martens use to move from one forest stand to another. 
Moreover, although we did not take habitat width explicitly into consideration, the application of a $100 \mathrm{~m}$ grain to the land-use map may have created large forest patches and eliminated narrow forest patches, forcing simulated cost paths to travel through large patches of suitable habitat. Model performance obtained at this grain size suggests that marten use large patches for movement, as observed by Hargis et al. [12]. The coarser map grain of $300 \mathrm{~m}$ may have generated large forested patches and also could have resulted in wideopen areas that were unsuitable for martens and which impeded movement, confirming that marten is sensitive to connectivity of suitable habitat [22]. We conclude that the least-cost path approach must be sensitive to grain because of gap crossing and sensitivity to connectivity of high quality habitat.

Broquet et al. [10] applied a resistance value 50 times higher in unforested and open areas ( $<20 \mathrm{y}$-old) than in forest and showed that $50 \times$ cost was better than no differencial cost. Model performance peaked in our analyses when resistance in open habitat was 20 times higher than in mature forest, but the location of this peak was unreliable. This result does not imply that open habitat is not resistant to movemet marten relative to other landcover types. Instead, the Montmorency Forest might not be heterogeneous enough in terms of habitat types and configuration to allow us to evaluate precisely relative movement resistance in open areas compared to mature forests. In south central Wyoming (USA), Cushman et al. [22] concluded that nonforest cover was resistant to American marten movement when it fragmented landscape (24\% clearcuts distributed heterogeneously). In a landscape that was highly dominated by closed-canopy forest, they showed that open areas were 16 times less avoided. Similarly, Schadt et al. [42] were unable to estimate movement resistance for Eurasian lynx $(\operatorname{Lyn} x \operatorname{lyn} x)$ in central Europe and explained it as a lack of variability in landscape connectivity. Spatial variability of habitat features must affect their impact on movement and the power to detect these relationships [43]. Koen et al. [17], who found no significant effect of landscapes features on genetic distance, argued that open habitat is not very resistant to marten movement relative to other landcover types at province-wide scale (Ontario). They suggest that landscape features influencing marten movement are different among spatial scales [15].

We are aware that better models may exist which we did not test. Resistance values and map grain sizes were set arbitrarily, and nontested values could have led to higher least-cost path performance. However, resistance values for open areas could not be set higher because of the least-cost paths following forest borders, together with the range of grain sizes that was used based on forest-management scales. The simplification of map resolution to a maximum three classes might not be the strongest landscape model explaining marten movements [31]. We restricted our models to a few number of habitat categories to show that assumptions about two landscape criteria (e.g., forest age and edges) can be sufficient to model movement resistance of a pronounced habitat specialist like the American marten. Further research on marten movement resistance in more heterogeneous landscapes could lead to generalization of least-cost path factors estimates at the forest management scale (spatial replication; [43, 44]). Also, snow-tracking could be criticized, because it generates strongly heterogeneous sampling effort in space. Heterogeneous sampling effort could add bias to distances; where transects were rare, distances between simulated and real tracks were possibly higher. This problem was resolved here by comparing those distances rather than using absolute ones. One might argue that statistical analyses could also be biased due to the spatial clustering of tracks of the same individual, which could be recorded several times on the same transect. However, our sampling units were not single tracks, but least-cost paths, for which a single distance (fit) metric was calculated for a given set of parameters. We thus avoided pseudoreplication attributable to repeated tracks from the same individual.

Forest management scenarios that are based on stand quality differ greatly from scenarios based on access, with the former focusing mostly on tree attributes (species, size, snags, debris, etc.) and the latter focusing mostly on the configuration of stands. Our study contributes to forest management by giving weight to access and, thus, to stand configuration issues. We showed that presence-only data can aid in the understanding of movement costs for marten in the boreal forest and the parameterization of spatial models. The choice of the correct map grain size seems to be crucial in spatially explicit simulation models. Although it was probably not significant to population persistence in our study, matrix resistance might thwart animal movements through more fragmented landscapes. More studies about American marten movement at a forest management scale would be useful to refine these models in more heterogeneous landscapes.

\section{Acknowledgments}

Financial support for this work was provided by an NSERC (Natural Sciences and Engineering research Council of Canada) Discovery Grant to AD. The authors would like to thank all of the field assistants and former students who contributed to the collection of the 5-year dataset. Thanks are also due to the five anonymous reviewers who examined the manuscript in detail, and to Bill Parsons for a thorough review of the English of the revised version. Material support was possible in the field thanks to the employees of the Montmorency Forest, and the authors are grateful to them for their help. The authors of this paper do not have a direct financial relation with the commercial identities mentioned in this paper that might lead to a conflict of interest for any of the authors.

\section{References}

[1] J. Martin, C. Calenge, P. Y. Quenette, and D. Allainé, "Importance of movement constraints in habitat selection studies," Ecological Modelling, vol. 213, no. 2, pp. 257-262, 2008.

[2] R. T. T. Forman and L. E. Alexander, "Roads and their major ecological effects," Annual Review of Ecology and Systematics, vol. 29, pp. 207-231, 1998. 
[3] M. Bélisle, "Measuring landscape connectivity: the challenge of behavioral landscape ecology," Ecology, vol. 86, no. 8, pp. 1988-1995, 2005.

[4] D. E. Bowler and T. G. Benton, "Causes and consequences of animal dispersal strategies: relating individual behaviour to spatial dynamics," Biological Reviews of the Cambridge Philosophical Society, vol. 80, no. 2, pp. 205-225, 2005.

[5] M. Bélisle and C. C. St. Clair, "Cumulative effects of barriers on the movements of forest birds," Conservation Ecology, vol. 5 , no. 2, 2001.

[6] J. R. Rhodes, C. A. Mcalpine, D. Lunney, and H. P. Possingham, "A spatially explicit habitat selection model incorporating home range behavior," Ecology, vol. 86, no. 5, pp. 1199 1205, 2005.

[7] F. Adriaensen, J. P. Chardon, G. De Blust et al., "The application of "least-cost" modelling as a functional landscape model," Landscape and Urban Planning, vol. 64, no. 4, pp. 233 247, 2003.

[8] D. H. Douglas, "Least-cost path in GIS using an accumulated cost surface and slopelines," Cartographica, vol. 31, no. 3, pp. 37-51, 1994.

[9] O. L. Sutcliffe, V. Bakkestuen, G. Fry, and O. E. Stabbetorp, "Modelling the benefits of farmland restoration: methodology and application to butterfly movement," Landscape and Urban Planning, vol. 63, no. 1, pp. 15-31, 2003.

[10] T. Broquet, N. Ray, E. Petit, J. M. Fryxell, and F. Burel, "Genetic isolation by distance and landscape connectivity in the American marten (Martes americana)," Landscape Ecology, vol. 21, no. 6, pp. 877-889, 2006.

[11] A. Desrochers, M. Bélisle, J. Morand-Ferron, and J. Bourque, "Integrating GIS and homing experiments to study avian movement costs," Landscape Ecology, vol. 26, no. 1, pp. 47-58, 2011.

[12] C. D. Hargis, J. A. Bissonette, and D. L. Turner, "The influence of forest fragmentation and landscape pattern on American martens," Journal of Applied Ecology, vol. 36, no. 1, pp. 157$172,1999$.

[13] P. Joly, C. Morand, and A. Cohas, "Habitat fragmentation and amphibian conservation: building a tool for assessing landscape matrix connectivity," Comptes Rendus_Biologies, vol. 326, no. 1, pp. S132-S139, 2003.

[14] S. F. Spear, N. Balkenhol, M. J. Fortin, B. H. McRae, and K. Scribner, "Use of resistance surfaces for landscape genetic studies: considerations for parameterization and analysis," Molecular Ecology, vol. 19, no. 17, pp. 3576-3591, 2010.

[15] T. N. Wasserman, S. A. Cushman, M. K. Schwartz, and D. O. Wallin, "Spatial scaling and multi-model inference in land-scape genetics: Martes americana in northern Idaho," Landscape Ecology, vol. 25, no. 10, pp. 1601-1612, 2010.

[16] L. Fahrig, "Non-optimal animal movement in human-altered landscapes," Functional Ecology, vol. 21, no. 6, pp. 1003-1015, 2007.

[17] E. L. Koen, J. Bowman, C. J. Garroway, S. C. Mills, and P. J. Wilson, "Landscape resistance and American marten gene flow," Landscape Ecology, vol. 27, no. 1, pp. 29-43, 2012.

[18] J. R. Row, G. Blouin-Demers, and S. C. Lougheed, "Habitat distribution influences dispersal and fine-scale genetic population structure of eastern foxsnakes (Mintonius gloydi) across a fragmented landscape," Molecular Ecology, vol. 19, no. 23, pp. 5157-5171, 2010.

[19] A. J. Shirk, D. O. Wallin, S. A. Cushman, C. G. Rice, and K. I. Warheit, "Inferring landscape effects on gene flow: a new model selection framework," Molecular Ecology, vol. 19, no. 17, pp. 3603-3619, 2010.
[20] K. Driezen, F. Adriaensen, C. Rondinini, C. P. Doncaster, and E. Matthysen, "Evaluating least-cost model predictions with empirical dispersal data: a case-study using radiotracking data of hedgehogs (Erinaceus europaeus)," Ecological Modelling, vol. 209, no. 2-4, pp. 314-322, 2007.

[21] S. A. Cushman and J. S. Lewis, "Movement behavior explains genetic differentiation in American black bears," Landscape Ecology, vol. 25, no. 10, pp. 1613-1625, 2010.

[22] S. A. Cushman, M. G. Raphael, L. F. Ruggiero, A. S. Shirk, T. N. Wasserman, and E. C. O'Doherty, "Limiting factors and landscape connectivity: the American marten in the Rocky Mountains," Landscape Ecology, vol. 26, no. 8, pp. 1137-1149, 2011.

[23] S. A. Cushman, M. Chase, and C. Griffin, "Mapping landscape resistance to identify corridors and barriers for elephant movement in Southern Africa," in Spatial Complexity, Informatics, and Wildlife Conservation, S. A. Cushman and F. Huettmann, Eds., pp. 349-367, Springer, New York, NY, USA, 2010.

[24] Environment Canada, "Canadian Climate Normals, 19712000 (Québec),” Canadian Climate Program, Québec., City, 2007.

[25] L. Bélanger, "La forêt mosaïque comme stratégie de conservation de la biodiversité de la sapinière boréale de l'Est: l'expérience de la Forêt Montmorency," Le Naturaliste Canadien, vol. 125, pp. 18-25, 2001.

[26] J. C. Halfpenny, R. W. Thompson, S. C. Morse, T. Holden, and P. Rezendes, "Snow tracking," in American Marten, Fisher, Lynx, and Wolverine: Survey Methods for Their Detection (Gen Tech Rep PSW-157), W. J. Zielinski and T. E. Kucera, Eds., chapter 5, USDA Forest Service, Pacific Southwest Research Station, Albany, Calif, USA, 1995.

[27] M. Elbroch, Mammal Tracks and Sign: A Guide to North American Species, Stackpole, Mechanicsburg, Pa, USA, 2003.

[28] E. L. Koen, J. Bowman, and A. A. Walpole, "The effect of cost surface parameterization on landscape resistance estimates," Molecular Ecology Resources. In press.

[29] F. Potvin, L. Bélanger, and K. Lowell, "Marten habitat selection in a clearcut boreal landscape," Conservation Biology, vol. 14, no. 3, pp. 844-857, 2000.

[30] É. Alvarez, La forêt mosä̈que: une alternative d'aménagement pour le maintien de la martre dans la sapinière boréale? [M.S. thesis], Université Laval, 1996.

[31] S. A. Cushman and E. L. Landguth, "Scale dependent inference in landscape genetics," Landscape Ecology, vol. 25, no. 6, pp. 967-979, 2010.

[32] J. A. Lee-Yaw, A. Davidson, B. H. McRae, and D. M. Green, "Do landscape processes predict phylogeographic patterns in the wood frog?" Molecular Ecology, vol. 18, no. 9, pp. 18631874, 2009.

[33] ESRI, ArcGIS® 9.3., Environmental Systems Research Institute, Inc., Redlands, Calif, USA, 2008.

[34] A. C. Smith and J. A. Schaefer, "Home-range size and habitat selection by American marten (Martes americana) in Labrador," Canadian Journal of Zoology, vol. 80, no. 9, pp. 1602-1609, 2002.

[35] I. D. Thompson and P. W. Colgan, "Numerical responses of martens to a food shortage in northcentral Ontario," Journal of Wildlife Management, vol. 51, no. 4, pp. 824-835, 1987.

[36] W. B. Robinson, "Coyote control with compound 1080 stations in national forests," Journal of Forestry, vol. 51, no. 12, pp. 880-885, 1953.

[37] H. Frouin, Influence des corridors routiers et des coupes sur les déplacements hivernaux de la martre d'Amérique en forêt boréale aménagée [M.S. thesis], Université Laval, 2011. 
[38] R. E. Cumberland, J. A. Dempsey, and G. J. Forbes, "Should diet be based on biomass? Importance of larger prey to the American marten," Wildlife Society Bulletin, vol. 29, no. 4, pp. 1125-1130, 2001.

[39] K. G. Poole and R. P. Graf, "Winter diet of marten during a snowshoe hare decline," Canadian Journal of Zoology, vol. 74, no. 3, pp. 456-466, 1996.

[40] C. Vigeant-Langlois and A. Desrochers, "Movements of wintering American marten (Martes americana): relative influences of prey activity and forest stand age," Canadian Journal of Forest Research, vol. 41, no. 11, pp. 2202-2208, 2011.

[41] K. Rothley, "Finding and filling the "cracks" in resistance surfaces for least-cost modeling," Ecology and Society, vol. 10, no. 1, article 4, 10p.

[42] S. Schadt, F. Knauer, P. Kaczensky, E. Revilla, T. Wiegand, and L. Trepl, "Rule-based assessment of suitable habitat and patch connectivity for the Eurasian lynx," Ecological Applications, vol. 12, no. 5, pp. 1469-1483, 2002.

[43] R. A. Short Bull, S. A. Cushman, R. MacE et al., "Why replication is important in landscape genetics: American black bear in the Rocky Mountains," Molecular Ecology, vol. 20, no. 6, pp. 1092-1107, 2011.

[44] G. Segelbacher, S. A. Cushman, B. K. Epperson et al., "Applications of landscape genetics in conservation biology: concepts and challenges," Conservation Genetics, vol. 11, no. 2, pp. 375-385, 2010. 

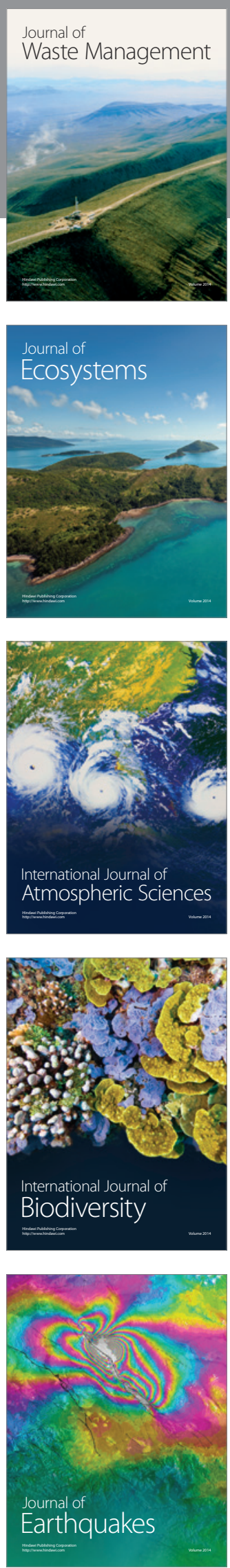
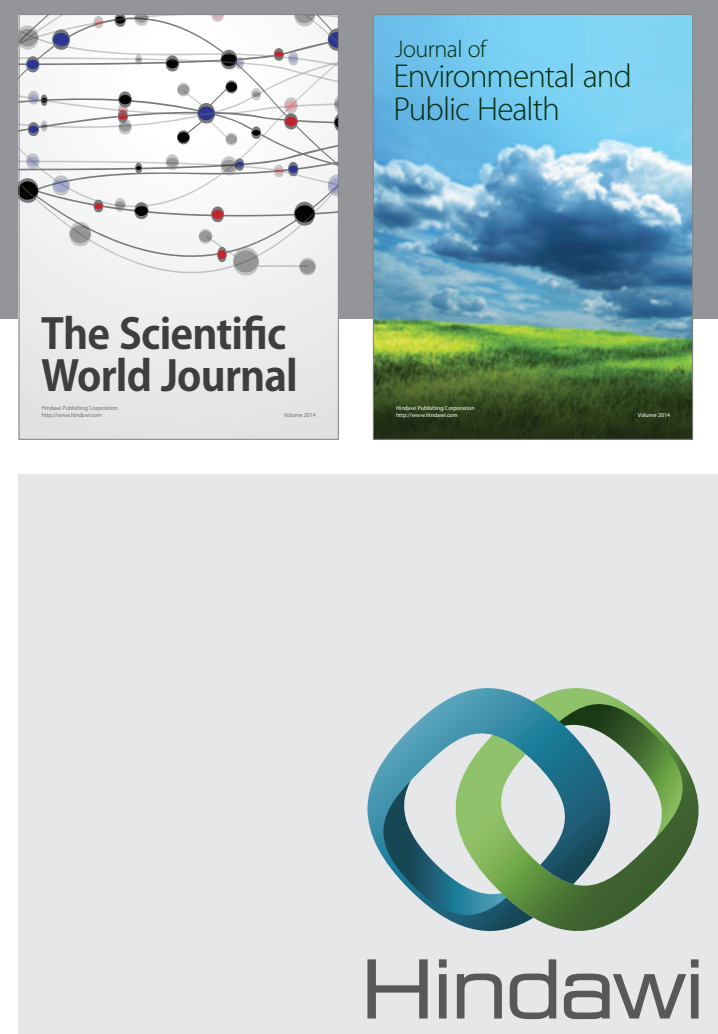

Submit your manuscripts at

http://www.hindawi.com
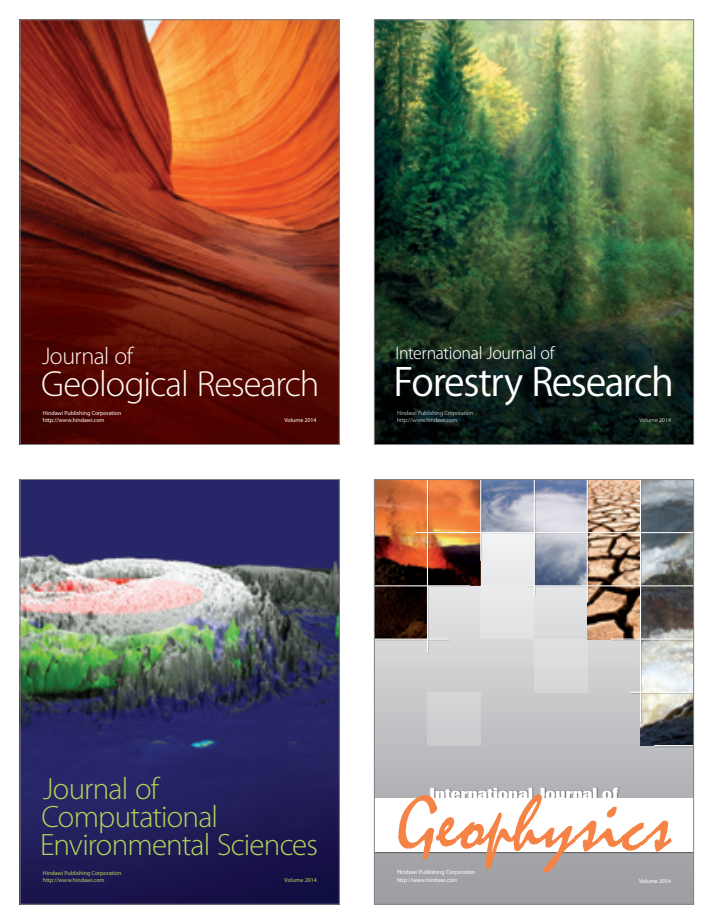
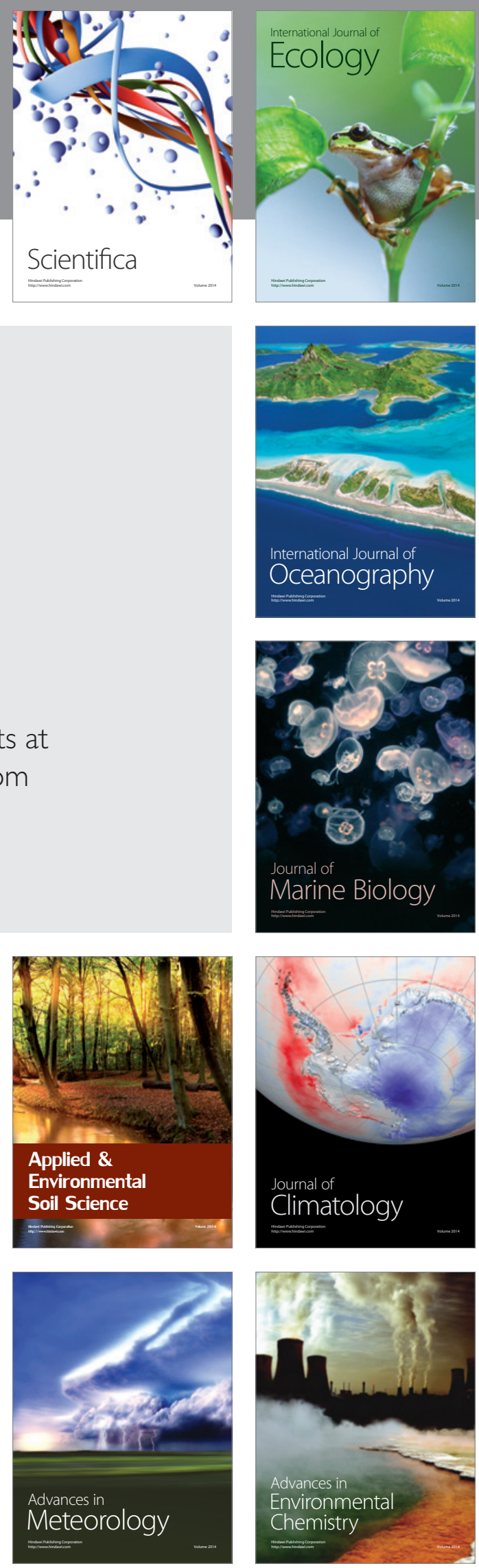